\title{
Simulating the Role of Subtropical Stratocumulus Clouds in Driving Pacific Climate Variability
}

\author{
KATINKA BELlomo AND Amy Clement \\ Rosenstiel School of Marine and Atmospheric Science, University of Miami, Miami, Florida \\ Thorsten MAuritsen, GaBy RÄDEL, AND BJORn STEVEnS \\ Max Planck Institute for Meteorology, Hamburg, Germany
}

(Manuscript received 9 September 2013, in final form 3 March 2014)

\begin{abstract}
This study examines the influence of the northeast and southeast Pacific subtropical stratocumulus cloud regions on the modes of Pacific climate variability simulated by an atmospheric general circulation model (ECHAM6) coupled to a slab ocean. The sensitivity of cloud liquid water to underlying SST is changed in the radiation module of the atmospheric model to increase the strength of positive low-cloud feedback in the two regions. Enhanced low-cloud feedback increases the persistence and variance of the leading modes of climate variability at decadal and longer time scales. Additional integrations show that the southeast Pacific influences climate variability in the equatorial ENSO region, whereas the effects of the northeast Pacific remain confined to the North Pacific. The results herein suggest that a positive feedback among SST, cloud cover, and large-scale atmospheric circulation can explain decadal climate variability in the Pacific Ocean. In particular, cloud feedbacks over the subtropical stratocumulus regions set the time scale of climate variability. A proper representation of low-level cloud feedbacks in the subtropical stratocumulus regions could therefore improve the simulation of Pacific climate variability.
\end{abstract}

\section{Introduction}

Several studies have documented low-frequency fluctuations in Pacific Ocean sea surface temperature (SST) associated with basinwide changes in climate. These fluctuations are characterized by a triangular pattern of SST anomalies over the eastern side of the Pacific Ocean, surrounded by anomalies of the opposite sign to the west, and over the central North and South Pacific. This pattern is usually referred to as Pacific decadal variability (PDV) and represents the primary mode of Pacific climate variability on time scales longer than interannual (Chen et al. 2008).

Over the twentieth century, a shift from cold to warm PDV occurred in 1924-25, followed by a shift from warm to cold in 1946-47, and from cold to warm in 1976-77. The latest shift to a cold phase seems to have occurred

Corresponding author address: Katinka Bellomo, Rosenstiel School of Marine and Atmospheric Science, University of Miami, 4600 Rickenbacker Causeway, Miami, FL 33149.

E-mail: kbellomo@rsmas.miami.edu after the major El Niño event of 1997-98, and still persists (Nitta and Yamada 1989; Trenberth and Hurrell 1994; Mantua et al. 1997; Zhang et al. 1997; Deser et al. 2004; Alexander 2010; Deser et al. 2010; Wang et al. 2014, among others). The shifts in PDV were accompanied by changes in large-scale atmospheric circulation, sea level pressure (SLP) over the Aleutian low, air temperature, and rainfall over North America (e.g., Mantua et al. 1997; Minobe 1997; Hare and Mantua 2000; McCabe et al. 2004; Deser et al. 2004), and had far reaching consequences on marine ecosystems and fish production (e.g., Mantua and Hare 2002; Peterson and Schwing 2003; Di Lorenzo et al. 2008).

In the tropical Pacific, the low-frequency SST fluctuations of the PDV resemble interannual anomalies associated with El Niño-Southern Oscillation (ENSO), and are similarly accompanied by changes in the Walker circulation and precipitation. These low-frequency fluctuations in the tropical Pacific are often referred to as ENSO-like decadal variability (e.g., Wang and Ropelewski 1995; Zhang et al. 1997; Clement et al. 2011) and are linked to persistent rainfall anomalies over land such 
as the Dust Bowl drought of the 1930s (Barlow et al. 2001; Hoerling et al. 2001; Schubert et al. 2004a,b; Seager et al. 2005). Given the substantial economic and societal impacts of PDV, understanding the processes responsible for the persistence of SST anomalies in the tropical Pacific is of primary importance because a better understanding of these processes improves predictability of decadal changes in SST, which is currently limited (Kim et al. 2012; Smith et al. 2012).

The mechanisms underlying PDV are under debate (Alexander 2010). Given the similarity between SST patterns associated with PDV and ENSO, most studies have suggested mechanisms for PDV that presume a fundamental role for coupled ocean-atmosphere dynamics and ocean waves (e.g., Latif and Barnett 1994; $\mathrm{Gu}$ and Philander 1997; Timmermann and Jin 2002; Karspeck et al. 2004; Yeh and Kirtman 2006; Kwon and Deser 2007). More recently, a few studies challenged this notion, and showed that atmospheric dynamics and air-sea interactions can alone explain ENSO-like variability on both interannual (Dommenget 2010) and longer time scales (Dommenget and Latif 2008; Clement et al. 2011; Okumura (2013)). These studies examined AGCMs coupled to a motionless slab ocean model (AGCM-slab simulations) in which the atmospheric model is thermodynamically but not dynamically coupled to the ocean model. Clement et al. (2011) showed that ENSO-like low-frequency variability simulated by an ensemble of AGCM-slab models from the Coupled Model Intercomparison Project phase 3 (CMIP3) archive shares several features with observations, including precipitation, sea level pressure, and atmospheric circulation patterns. Those authors found that the persistence of ENSO-like SST anomalies in the AGCM-slab models is consistent with an integration of atmospheric white noise by the oceanic mixed layer [i.e., as in the theoretical model of Frankignoul and Hasselmann (1977)]. In this context, the duration of the SST anomalies is regulated by weakly damped atmospheric feedbacks involving the interaction among SST, winds, and cloud cover. Clement et al. (2011) also showed that the persistence of SST anomalies in the tropical Pacific is model dependent.

Low-level clouds over the subtropical eastern Pacific exert a strong radiative cooling and increase the persistence of local SST anomalies in the northeast (NE) and southeast (SE) Pacific subtropical stratocumulus regions (Klein and Hartmann 1993; Park et al. 2005; Clement et al. 2009; Bellomo et al. 2014). Ma et al. (1996) increased the amount of stratocumulus cloud cover over the SE Pacific off the coasts of Peru in a coupled climate model. They found that greater cloud cover reduces the warm SST bias in the SE Pacific and results in a better simulation of precipitation and trade winds across the tropical Pacific. Several other studies have then suggested that there is a positive feedback among subtropical low-level clouds, SST, and large-scale atmospheric circulation in the tropical Pacific (Philander et al. 1996; Nigam 1997; Norris 2005; Clement et al. 2009). The SST anomalies propagate from the subtropical NE and SE Pacific regions to the equatorial Pacific via the atmospheric wind-evaporation-SST (WES) feedback (Zhou and Carton 1998) and influence ENSO and the tropical Pacific climate (Chang et al. 2007; Matei et al. 2008; Okumura (2013); Zhang et al. 2014). Cloud feedback in the subtropical stratocumulus regions could therefore lead to decadal anomalies in SST throughout the Pacific basin (cf. Clement et al. 2009).

In this study we examine the hypothesis that low-level cloud feedback influences the persistence of tropical Pacific climate variability patterns. We increase the strength of positive low-cloud feedback over the NE and SE Pacific subtropical stratocumulus regions in an AGCM-slab model, and evaluate the influence of these regions on the modes of Pacific climate variability simulated by the model. This investigation gives important insights into the role of low-level clouds with regard to the persistence of SST anomalies, and indicates that a better representation of clouds could increase the predictive skill of decadal climate variability in the Pacific Ocean.

\section{Data and methods}

\section{a. Experimental design}

We perform experiments with the ECHAM6 (v6.1.04) atmospheric general circulation model coupled to a slabocean model for the open ocean and a thermodynamical sea ice model. The details of ECHAM6 are given in Stevens et al. (2013). We use a variant of the coarseresolution model (ECHAM6-CR) with T31 horizontal grid $\left(3.75^{\circ} \times 3.75^{\circ}\right)$ and 31 vertical levels instead of 47 . The coarse-resolution version, unlike the other versions of ECHAM6, does not include a representation of the stratosphere. The mixed-layer depth of the slab-ocean model is fixed to $50 \mathrm{~m}$ everywhere and does not vary seasonally. When the AGCM is coupled to a slab ocean, the atmosphere and the ocean are thermodynamically but not dynamically coupled. We choose this configuration because AGCM-slab models simulate realistic low-frequency Pacific climate variability even in the absence of ocean dynamics (Clement et al. 2011), and it is easier to interpret the effects due to atmospheric feedbacks without the complications of dynamical coupling with an interactive ocean.

We perform a simulation in preindustrial control conditions (i.e., constant greenhouse gas forcing), which 

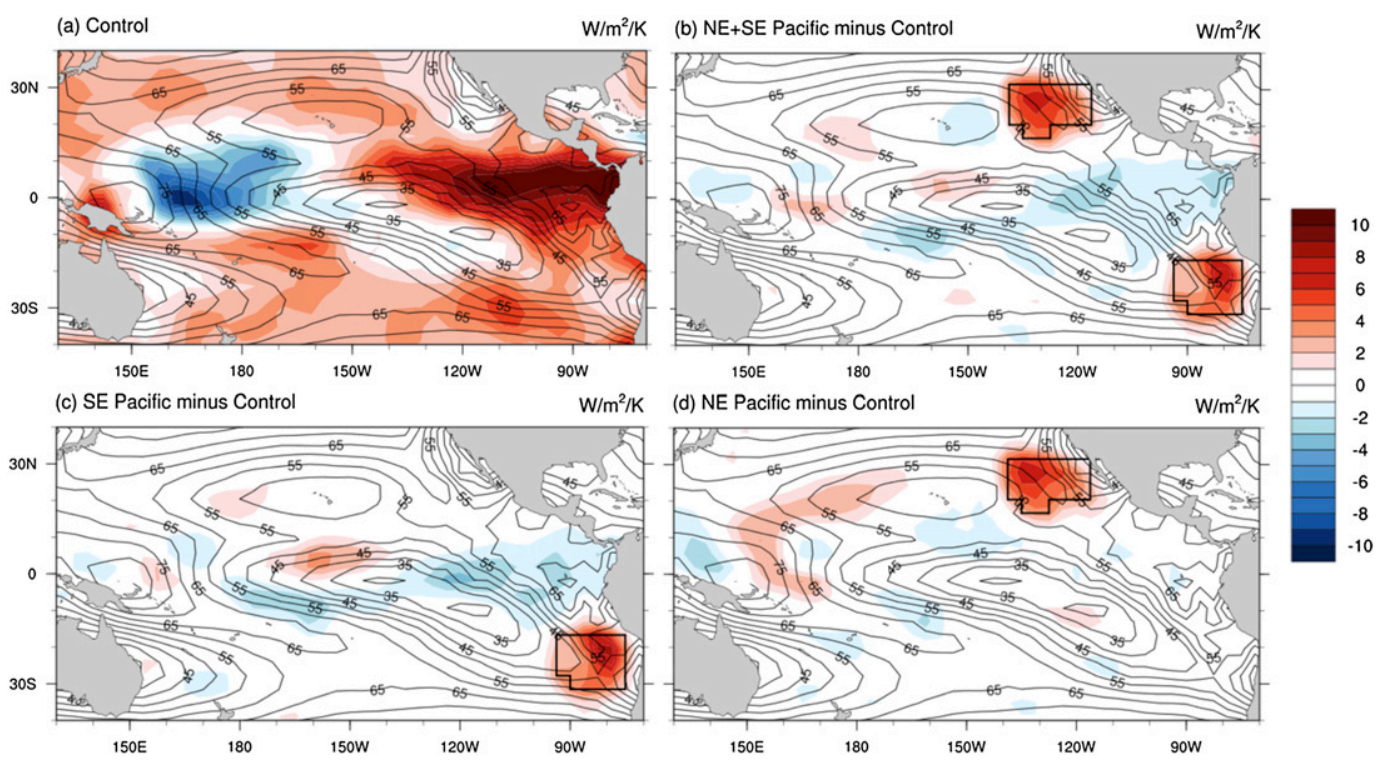

FIG. 1. (a) Cloud feedback in the control simulation (estimated as regression of CRE at the surface on SST). Also shown is the difference in the strength of cloud feedback between the three experiments and the control run: (b) NE+SE Pacific minus control, (c) SE Pacific minus control, and (d) NE Pacific minus control. Overlain is cloud cover climatology from the control run. Black boxes indicate where low-cloud feedback is enhanced.

we will refer to as the control run. In AGCM-slab ocean simulations, SST is determined at each time step by atmospheric heat fluxes in the current run and prescribed monthly mean ocean heat fluxes-commonly referred to as $q$ fluxes-which represent the effects of the mean ocean heat transport but do not drive internal variability. We compute $q$ fluxes from a run of the AGCM forced with fixed climatological monthly mean SST.

We compare the control run with simulations in which we enhance the strength of positive low-cloud feedback, where positive means an amplification of a local SST anomaly. To increase the strength of positive low-cloud feedback we multiply cloud liquid water in the radiation code of ECHAM6 by an amplification factor $y$ at each time step of the model run. The factor $y$ is a function of underlying SST and ranges between 0 and 2 as follows:

$$
y=1-\arctan (\operatorname{SST})(2 / \pi)
$$

where SST is the monthly mean SST anomaly calculated as the SST in the current run minus the climatological monthly mean SST computed from the last 50 years of the control run. In other words, at each time step and grid point the model checks which month it is, calculates the monthly mean SST anomaly with respect to the control simulation, and computes $y$. Then, the cloud liquid water is multiplied by $y$ and becomes a function of the underlying monthly SST anomaly.

By changing the radiative effect of cloud liquid water seen by the radiation module with Eq. (1), we modify the cloud radiative effect (CRE). In this study we only show the CRE at the surface, which is defined as totalsky minus clear-sky net (i.e., shortwave plus longwave) radiative flux at the surface and is positive for downward fluxes. Our conclusions do not change when we examine the CRE at the top of the atmosphere. Equation (1) shows that when SST is positive the net cloud radiative effect decreases (warming effect) because cloud liquid water is multiplied by $y<1$, whereas when SST is negative net CRE increases (cooling effect) because cloud liquid water is multiplied by $y>1$. This increases the strength of positive cloud feedback in the model.

We increase the strength of positive cloud feedback over the NE and SE Pacific, which we define as the subtropical regions (i.e., outside $15^{\circ} \mathrm{N}-15^{\circ} \mathrm{S}$ ) where the mean subsidence at $500 \mathrm{hPa}$ is greater than $10 \mathrm{hPa} \mathrm{day}^{-1}$, and the lower tropospheric stability (LTS) is greater than $17.5 \mathrm{~K}$ (LTS is defined as the difference in potential temperature at 700 and $1000 \mathrm{hPa}$ ). This definition is somewhat arbitrary, but it allows us to target regions and atmospheric conditions in which subtropical stratocumulus clouds are predominant in the climatological mean of the model (cf. Medeiros and Stevens 2011). The regions that we choose are contoured by black boxes in Fig. 1. We verify that in these regions cloud liquid water in the model is present only in clouds below $700 \mathrm{hPa}$ in the climatological mean so that we enhance the strength of cloud feedback at low levels. We note that we only modify the radiative effect of cloud 
liquid water in the radiation module, and thus we do not change cloud liquid water in the atmospheric water budget.

We perform three experiments with enhanced lowcloud feedback. The first experiment is one in which we increase the strength of positive low-cloud feedback in both the NE and SE Pacific subtropical stratocumulus regions. This experiment will be referred to as the NE+SE Pacific simulation. The second experiment is one in which we enhance positive low-cloud feedback only in the SE Pacific (SE Pacific simulation) while in the third experiment we enhance positive low-cloud feedback only in the NE Pacific (NE Pacific simulation). All simulations, including the control run, are integrated for 200 years, but the first 50 years are discarded from the analysis to allow the model to spin up. We form monthly mean anomalies by subtracting the climatological monthly mean from each month. Each experiment is run with prescribed ocean heat fluxes calculated from AGCM simulations with fixed SST.

The difference in the long-term global mean SST between the three experiments with enhanced low-cloud feedback and the control run is less than $0.4 \mathrm{~K}$. We verified that this increase in mean SST does not affect our conclusions by running another experiment in which we modified the $q$ flux so that the mean SST change was nearly zero $(0.07 \mathrm{~K})$. In this simulation (not shown) we find consistent results with the ones shown in the rest of this paper. This means that changes in the mean climate do not affect the changes in internal climate variability due to enhanced cloud feedbacks. We also note that the enhanced cloud feedback does not influence the simulation of the seasonal cycle of SST.

\section{b. Observations}

We compare the model simulation of cloud feedback with observations. CRE is obtained from the Clouds and Earth's Radiant Energy System (CERES) Energy Balanced and Filled (EBAF) dataset (EBAF_Ed2.6r; Loeb et al. 2009). SST is from the Extended Reconstructed SST version $3 b$ (ERSSTv3b) dataset of the National Oceanic and Atmospheric Administration (NOAA) Earth System Research Laboratory (Smith et al. 2008). As with model simulations, we form monthly mean anomalies by subtracting the climatological monthly mean from each month using the years 2001-09 in which the two datasets overlap.

\section{Results}

\section{a. Enhanced strength of cloud feedback}

We estimate the strength of cloud feedback as the regression of local CRE (defined at surface throughout this study) on SST. Figure 1 shows cloud feedback in the control simulation (Fig. 1a) as well as the differences between the three enhanced cloud feedback experiments and the control run (Figs. 1b-d). Contours represent cloud cover climatology in the control run, while the black boxes indicate the regions where we increased the strength of cloud feedback applying Eq. (1).

Figure 1a shows that the model simulates positive cloud feedback over the eastern Pacific and negative cloud feedback over the equatorial western Pacific. Therefore, the model simulates cloud feedback of the same sign as seen in observations over the tropical $\mathrm{Pa}$ cific (Bellomo et al. 2014) but overestimates the strength of positive cloud feedback over some regions (e.g., the cold tongue) and underestimates it over the subtropical stratocumulus regions. In fact, the observational estimates of cloud feedback defined as the regression of CRE at the surface from CERES on SST from ERSST are $5.5 \mathrm{~W} \mathrm{~m}^{-2} \mathrm{~K}^{-1}$ over the NE Pacific and $4.2 \mathrm{~W} \mathrm{~m}^{-2} \mathrm{~K}^{-1}$ over the SE Pacific, while in the control simulation they are 1.6 and $2.7 \mathrm{~W} \mathrm{~m}^{-2} \mathrm{~K}^{-1}$, respectively. Although we increase the strength of cloud feedback in the subtropical stratocumulus regions, in this study we perform sensitivity tests to qualitatively explore the role of cloud feedbacks on Pacific climate variability, but we are not in a position yet to assess their actual magnitude. Therefore, we will compare the enhanced cloud feedback experiments with the control simulation but not with observations. Other estimates of strength of cloud feedback over the Pacific subtropical stratocumulus regions and the deficiency of models in simulating strong enough cloud feedback can be found in previous studies (e.g., Bony and Dufresne 2005; Cronin et al. 2006; Clement et al. 2009; Lauer et al. 2010; de Szoeke et al. 2012).

Figure $1 b$ shows that the NE+SE Pacific simulation exhibits stronger cloud feedback over both the NE and SE Pacific than in the control simulation, as intended. Figures 1c and 1d similarly show that cloud feedback gets stronger mainly over the SE Pacific and NE Pacific in the other two experiments, with smaller effects outside of these regions. Although some regions exhibit less positive cloud feedback (e.g., over the cold tongue), the sign of cloud feedback in the three experiments is of the same sign as in the control simulation (Fig. 1a) everywhere. Therefore, the sign of cloud feedback is consistent with observations in all simulations. The average cloud feedback over the NE and SE Pacific is reported in Table 1 for each experiment.

\section{b. Effects of cloud feedback on internal climate variability}

The stronger low-cloud feedbacks over the subtropical stratocumulus regions increase the magnitude 
TABLE 1. Average cloud feedback in the NE and SE Pacific regions in each simulation. Units are $\mathrm{W} \mathrm{m}^{-2} \mathrm{~K}^{-1}$.

\begin{tabular}{lcccc}
\hline \hline & $\begin{array}{c}\text { Control } \\
\text { exp. }\end{array}$ & $\begin{array}{c}\text { NE+SE } \\
\text { Pacific }\end{array}$ & $\begin{array}{c}\text { SE } \\
\text { Pacific }\end{array}$ & $\begin{array}{c}\text { NE } \\
\text { Pacific }\end{array}$ \\
\hline NE Pacific region & 1.6 & 5.7 & 1.5 & 5.7 \\
SE Pacific region & 2.7 & 7.2 & 7.3 & 2.4 \\
\hline
\end{tabular}

of monthly mean SST anomalies over the eastern $\mathrm{Pa}$ cific. Figure 2a shows the variance of SST in the control simulation, while Figs. 2b-d are the differences between the variance of SST in the enhanced cloud feedback experiments and the control run. Stippling indicates where the differences in the variance are statistically significant at the $95 \%$ level of a Fischer's $F$ test. To calculate the $F$ test, we use reduced degrees of freedom to account for the autocorrelation of the time series at lag 1 .

The variance of SST increases in the eastern Pacific, mostly where cloud feedbacks are enhanced, but also outside of these regions. In particular, there is an increase over the eastern equatorial Pacific and the cold tongue, which originates from the SE Pacific region. Compared to observations, we note that the model underestimates the variance of SST over the equatorial Pacific in the control simulation (Fig. 2a). This is due to the absence of ocean dynamics and of ENSO (Clement et al. 2011). We note that there is not much increase in variance in the lower left corner of the SE Pacific box. This is related to the fact that the increase in strength of cloud feedback is less pronounced there due to less cloud cover in the climatological mean (Fig. 1b).

Cloud feedbacks also have a considerable impact on the persistence of SST monthly mean anomalies, as shown in Fig. 3 by the difference between the $e$-folding time scale in the three experiments and the control run. The $e$-folding time scale is defined as the month at which the autocorrelation of SST reduces by a factor of 1/e and is a measure of the persistence of SST anomalies. For reference, we plot the $e$-folding time scale in the control simulation in Fig. 3a. In the control simulation (Fig. 3a), the $e$-folding time scale exhibits the largest values along the equatorial Pacific and the cold tongue, and over the subtropical eastern Pacific off the coasts of California and Peru. The NE+SE Pacific experiment (Fig. 3b) exhibits the largest change from the control run, that is, an increase in $e$-folding time scale by $\sim 7$ months, which occurs over the Niño-3.4 region $\left(5^{\circ} \mathrm{S}-5^{\circ} \mathrm{N}, 120^{\circ}-170^{\circ} \mathrm{W}\right)$ and almost doubles the $e$-folding time scale of the control run in this region (Fig. 3a). Figures $3 \mathrm{c}$ and $3 \mathrm{~d}$ show similar results, in particular that the SE Pacific has a larger effect on SST in the equatorial ENSO region than the NE Pacific.

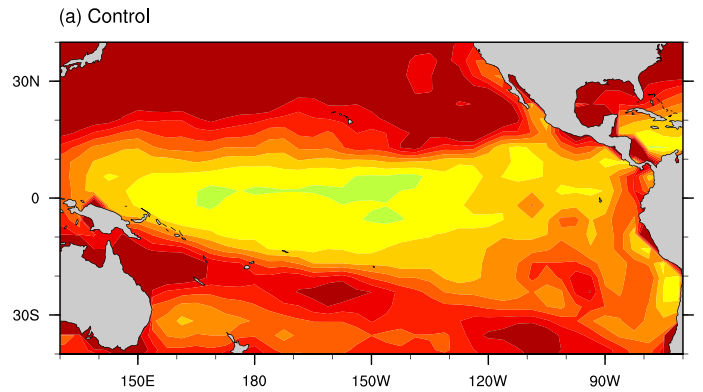

(c) SE Pacific minus Control

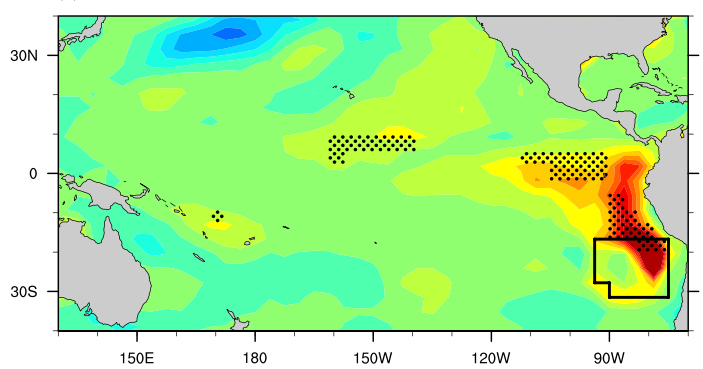

(b) NE+SE Pacific minus Control

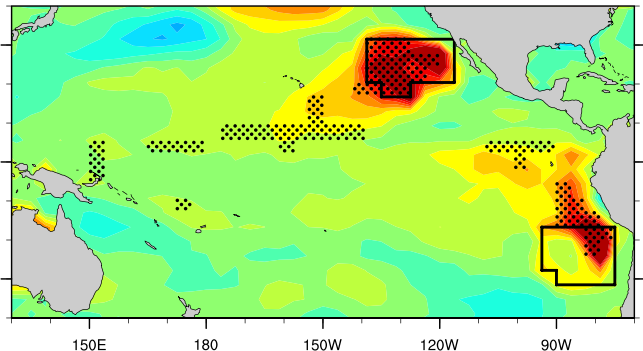

(d) NE Pacific minus Control

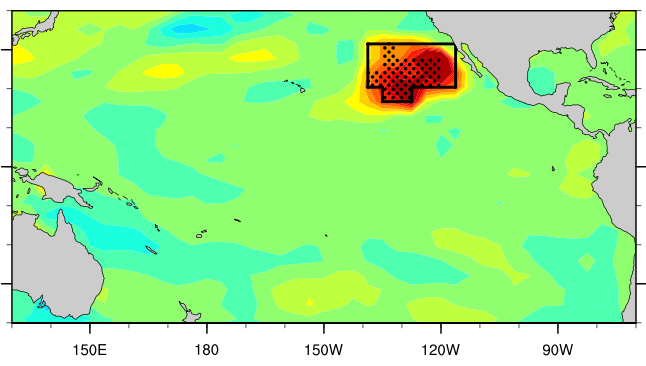

variance

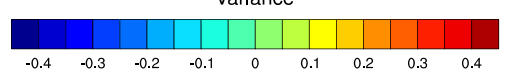

FIG. 2. (a) Variance of SST in the control simulation, and the difference in variance of SST between the three experiments and the control: (b) NE+SE Pacific minus control, (c) SE Pacific minus control, and (d) NE Pacific minus control. 

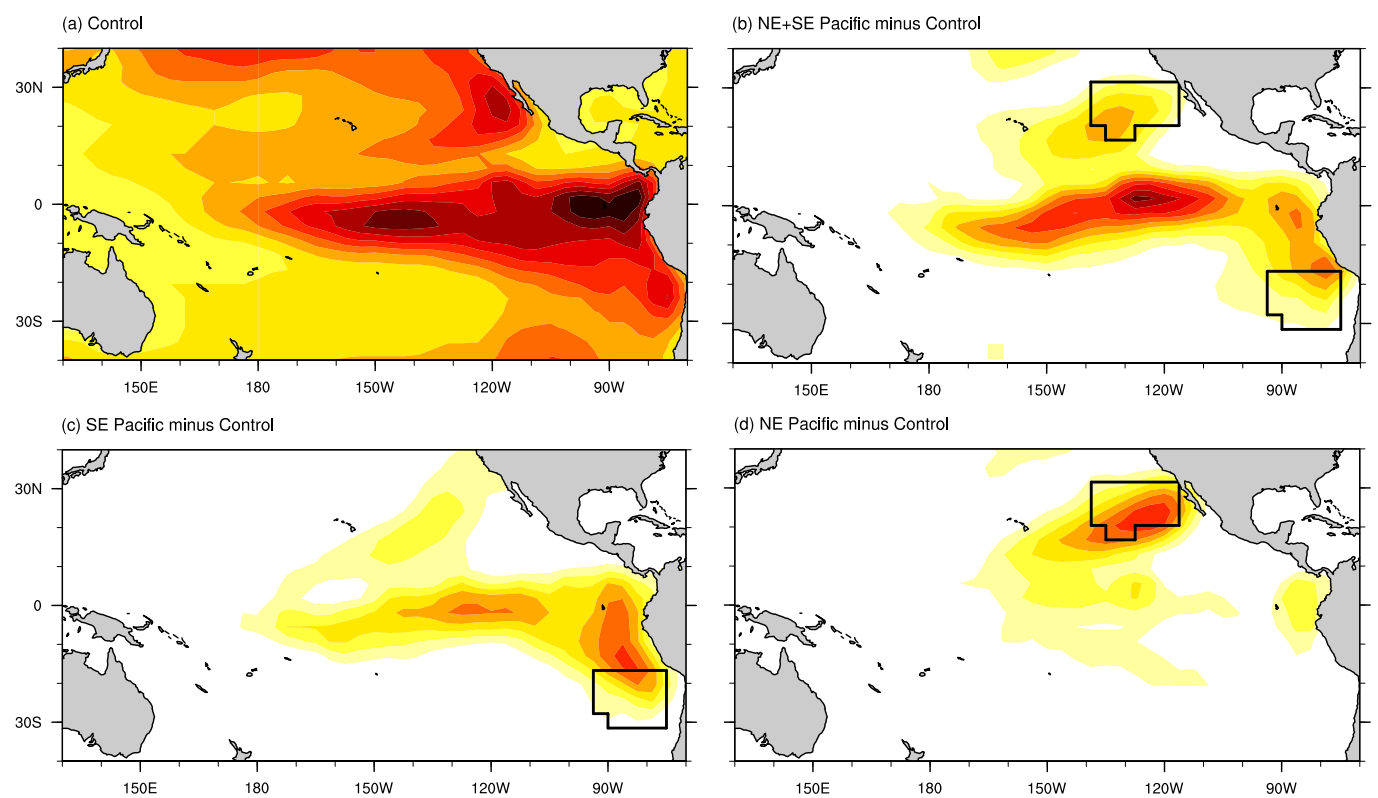

(d) NE Pacific minus Control
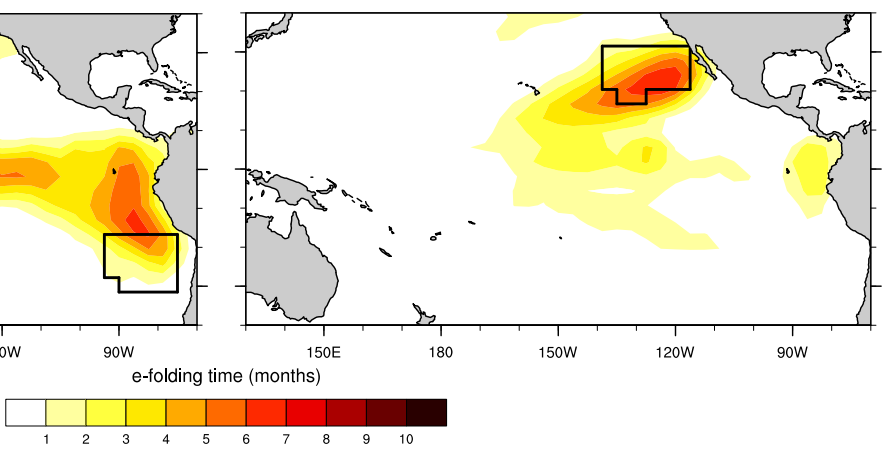

FIG. 3. (a) The $e$-folding time scale in the control simulation, and the difference in $e$-folding time scale between the three experiments and the control: (b) NE+SE Pacific minus control, (c) SE Pacific minus control, and (d) NE Pacific minus control.

These results indicate that cloud feedbacks influence the magnitude of SST anomalies and their persistence. To understand what is the effect of cloud feedback on the modes of climate variability simulated by the model, and to better characterize the relative influences from the NE and SE Pacific regions, we compare the mean climate state (Fig. 4) with an empirical orthogonal function (EOF) analysis of the leading modes of variability (Fig. 5).

Figure 4 shows the climatology of SST (shaded), SLP (contours), and surface winds (vectors) in the control simulation. As in observations, the subtropical stratocumulus regions (boxed) are characterized by relatively cold SST and are located equatorward and westward of the subtropical high pressure systems. To obtain the leading modes of climate variability in the tropical Pacific Ocean, we compute EOFs of tropical Pacific SST $\left(30^{\circ} \mathrm{S}-30^{\circ} \mathrm{N}, 140^{\circ} \mathrm{E}-70^{\circ} \mathrm{W}\right)$, and then use the Kaiser row normalization and the varimax rotation to obtain the first two rotated EOFs in each model simulation. After the rotation, the EOFs are orthogonal but the principal components (PCs) are not. The PCs of the first two rotated EOFs are then normalized by their standard deviation.

Figure 5 shows the regression of SST, surface winds, and SLP on the PCs of the first two rotated EOFs in the control run. These regressions represent the anomalies associated with the sign of SST (shaded) shown in the plots. When these modes shift to the opposite phase with reversed SST sign, the anomalies associated with the opposite phase have the same pattern as those shown in the plots in Fig. 5 but reversed sign.

The first EOF explains $10 \%$ of the variance and the regression on its PC (Fig. 5a) shows a pattern of

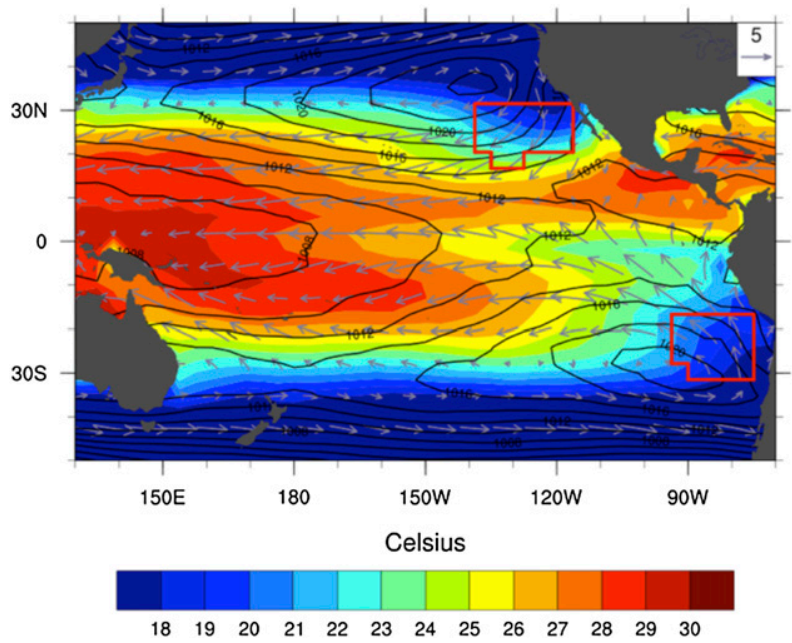

FIG. 4. Climatology in the control simulation: SST (shaded), SLP (contours) ranging from 990 to $1040 \mathrm{hPa}$ with 2-hPa intervals, and (vectors) and surface winds in $\mathrm{ms}^{-1}$. 
(a) Regression on the North Pacific mode

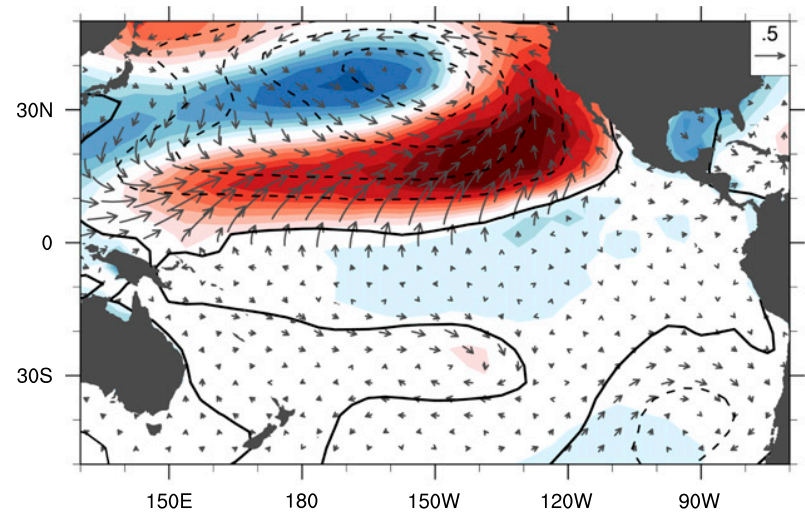

(b) Regression on the South Pacific mode

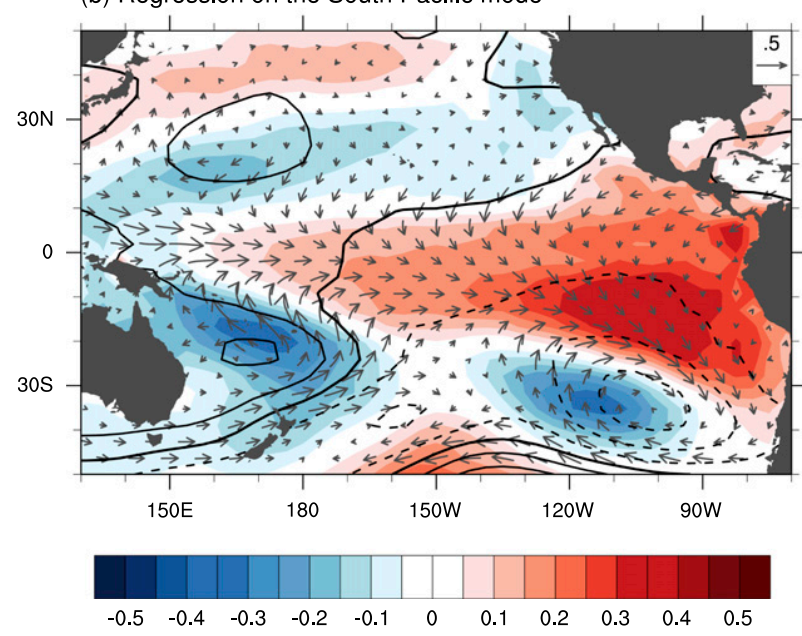

FIG. 5. Regression of SST (shaded), surface winds (vectors), and SLP (contours) on the PCs of the (a) North Pacific mode and (b) South Pacific mode in the control simulation. The PCs are normalized by their standard deviation. Negative SLP contours are dashed, positive SLP contours are solid, and the zero SLP contour is thick solid. Contour range is from -2 to $2 \mathrm{hPa}$, with a 0.2 interval and surface winds are in $\mathrm{m} \mathrm{s}^{-1}$.

variability resembling the Pacific decadal oscillation (PDO), which is the North Pacific signature of PDV (Mantua et al. 1997). During the positive phase of the PDO, the Aleutian low and the cyclonic wind circulation around the low are enhanced, and SST anomalies over the central North Pacific and eastern Pacific Ocean are of opposite sign. These features are all captured by the first EOF of the control run (Fig. 5a). We will refer to this pattern as the North Pacific mode.

The second EOF explains similar variance $(9.8 \%)$ and the regression on its PC (Fig. 5b) is reminiscent of ENSO although the largest variance occurs over the southeast Pacific rather than at the equator because of the absence of ocean dynamics in the slab-ocean model configuration. This mode resembles the thermally coupled Walker (TCW) mode of Clement et al. (2011). Those
TABLE 2. Variance explained by the North Pacific and South Pacific modes in each simulation.

\begin{tabular}{lcccc}
\hline \hline & Control & $\begin{array}{c}\text { NE+SE } \\
\text { Pacific }\end{array}$ & $\begin{array}{c}\text { SE } \\
\text { Pacific }\end{array}$ & $\begin{array}{c}\text { NE } \\
\text { Pacific }\end{array}$ \\
\hline North Pacific mode & $10.0 \%$ & $13.4 \%$ & $11.0 \%$ & $12.8 \%$ \\
South Pacific mode & $9.8 \%$ & $13.5 \%$ & $15.3 \%$ & $10.2 \%$ \\
\hline
\end{tabular}

authors showed that the TCW mode is associated with interannual to decadal time scale fluctuations in the Southern Oscillation index, and arises even in the absence of ocean dynamics. Similarly to Clement et al. (2011), we find that the warm phase of this mode (Fig. 5b) is characterized by warm SST and westerly wind anomalies along the equatorial Pacific, a low and cyclonic wind circulation over the SE Pacific, and weaker Walker circulation. We will refer to this second regression as the South Pacific mode.

The North and South Pacific modes are the two dominant modes of Pacific climate variability simulated by the model, and explain similar variances. Linear crosscorrelations of the principal components associated with the two modes reveal that they are weakly correlated at lag 0 but this correlation (0.16) is small and not significant (at the $85 \%$ level confidence of a Pearson's $R$ test for correlation). Thus, even after the rotation of the EOFs, these two modes exist as separate patterns of variability in the model.

The experiments with enhanced positive low-cloud feedback over the subtropical stratocumulus regions simulate the same two dominant modes of variability, but the variance explained by the two modes is larger. Table 2 shows the variance explained by the two modes in each experiment. In the NE+SE Pacific experiment the variance of the two modes increases by about the same amount. Instead, the other two experiments show that the SE Pacific increases mainly the variance of the South Pacific mode, whereas the NE Pacific increases mainly the variance of the North Pacific mode. It is noteworthy that the North Pacific mode (Fig. 5a) remains confined to the Northern Hemisphere, whereas the South Pacific mode (Fig. 5b) reaches the equatorial ENSO region, which is consistent with previous studies. In fact, Okumura (2013) and Zhang et al. (2014) suggested that the mean location of the intertropical convergence zone (ITCZ) in the Northern Hemisphere prevents the wind-induced anomalies from the Northern Hemisphere from reaching the equator, and our findings support this idea (cf. wind patterns in Figs. 5a and $5 \mathrm{~b}$ with wind climatology in Fig. 4).

We note that the third EOFs in all experiments explain variances ranging from $6.3 \%$ to $7.0 \%$. Because these remain similar in all experiments while the first 
two EOFs increase in variance when low-cloud feedback is stronger, this means that the there is a shift of variability from smaller spatial scales to the large-scale leading modes. To test whether the values of variances explained by each EOF reported in Table 2 are robust, we perform a Monte Carlo test taking three intervals of 50 years each in the 150 years of the model simulations, and then we compute the EOFs for each interval. We find that the values reported in Table 2 are consistent in magnitude and within the range of the variances explained by the EOFs in each 50-yr interval.

The EOF analysis therefore shows that low-cloud feedbacks in the subtropical stratocumulus regions increase the variability of basinwide climate variability patterns. In particular, cloud feedback in the SE Pacific seems to play a fundamental role in modulating equatorial Pacific variability. To understand the influence of cloud feedback on equatorial climate variability as a function of time scale, we compute power spectra of the Niño-3 SST index (Fig. 6). The Niño-3 region $\left(5^{\circ} \mathrm{S}-5^{\circ} \mathrm{N}\right.$, $90^{\circ}-150^{\circ} \mathrm{W}$ ) is located in the eastern equatorial Pacific and is a commonly used index to detect ENSO variability. Although we choose to show the Niño-3 region, we find consistent results for other indices in the equatorial Pacific and the Niño-3.4 index. The power spectrum of the Niño-3 index in the control run is plotted in black (Fig. 6), while colored curves represent the power spectrum in the three experiments. In the calculation of the spectra we taper $10 \%$ of the data and apply a 15-month smoothing to the periodogram estimates.

The combined effects of the NE and SE Pacific feedbacks (red curve) increase the variance of the Niño-3 index at time scales longer than 10 years. Variance at time scales longer than 10 years is also enhanced by the SE Pacific (blue) and NE Pacific (green), although the influence of the NE Pacific at the equator is small. The SE Pacific (blue) increases interannual (2-7 yr) time scale variability, which suggests that SE Pacific cloud feedbacks could modulate ENSO amplitude on interannual time scales (Dommenget 2010).

The thin gray curves in Fig. 6 represent an estimate of the error range in the control run. The error range is obtained from the inverse chi-square distribution function at the $95 \%$ probability level by calculating the upper integration of the noncentral chi-square distribution from the degrees of freedom. The curves representing the NE+SE Pacific (red) and SE Pacific (blue) experiments lie well outside the error range, while the curve of the NE Pacific experiment is not statistically different from the control simulation. We also apply the Fischer's $F$ test for variances to show where the variances are statistically different from the control run. The black markers on the colored curves indicate at which frequencies the

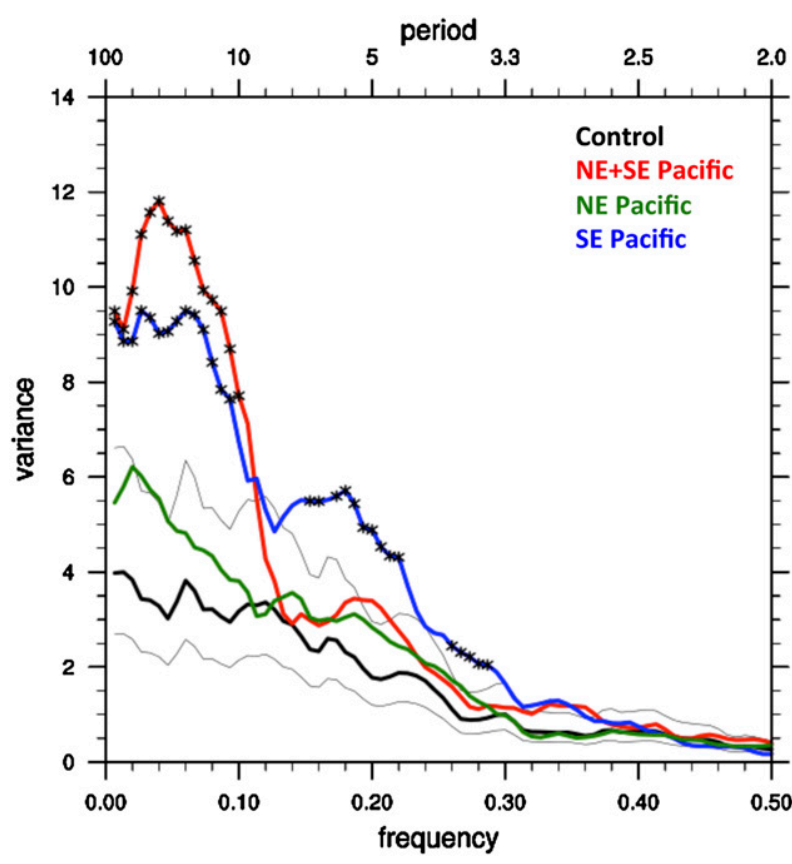

FIG. 6. Power spectra of the Niño-3 index in the control (black), NE + SE Pacific (red), SE Pacific (blue), and NE Pacific (green) simulations. Markers indicate where the variance is statistically different from the variance in the control simulation at the $95 \%$ level of a Fischer's $F$ test. Units are years for period and years ${ }^{-1}$ for frequency.

difference in the variance from the control simulation is significant at $95 \%$ level of the $F$ test. The Fischer's test shows that the enhanced variability at decadal and longer time scales in the NE+SE Pacific and SE Pacific experiments, and at interannual time scales in the SE Pacific, are statistically significant, in agreement with the estimated error range from the chi-square distribution.

We compute power spectra of SST indices in the NE and SE Pacific boxes and in the regions where the variance of SST increases by most in the subtropical eastern Pacific (not shown). We find an increase in the variance of SST at decadal and longer time scales and in the SE Pacific also at interannual time scales, consistent with the power spectra shown for the Niño-3 index in Fig. 6.

Interestingly, when the NE and SE Pacific feedbacks are both enhanced (red curve), they interfere constructively at decadal and longer time scales enhancing the variance of the Niño-3 index spectrum, but they interfere destructively at interannual time scales where the red curve (NE+SE Pacific) exhibits less variance than the blue curve (SE Pacific only). It is not clear what processes could lead to these different behaviors at interannual and decadal time scales, but additional analysis of composites of Niño-3 warm events in the NE+SE Pacific and control simulations (not shown) suggests that 
(a) Control

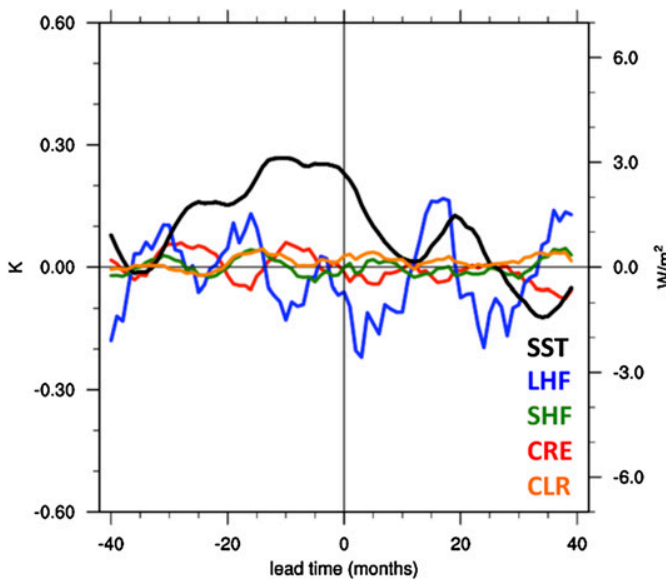

(b) SE Pacific

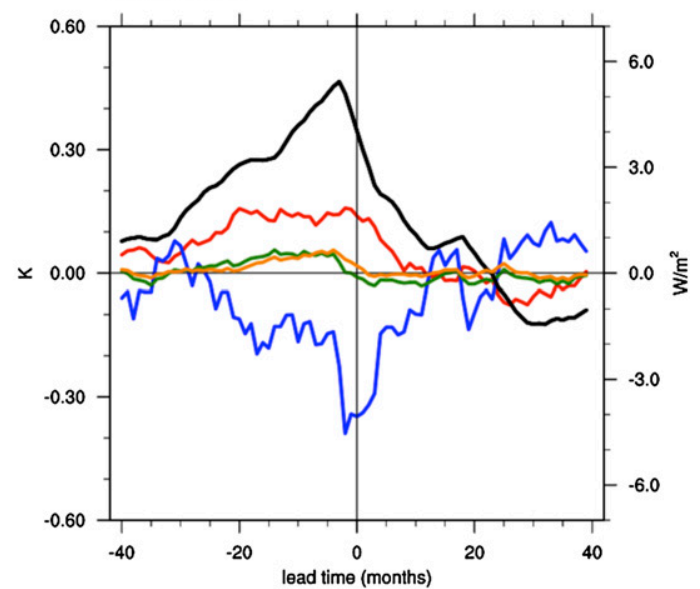

FIG. 7. Composites of Niño-3 index warm events in the southeastern Pacific $\left(5^{\circ}-30^{\circ} \mathrm{S}, 70^{\circ}-100^{\circ} \mathrm{W}\right)$, for the (a) control run and (b) SE Pacific run. All time series are smoothed with a 6-month running average. SST is plotted in black, latent heat flux (LHF) in blue, sensible heat flux (SHF) in green, cloud radiative effect (CRE) in red, and clear-sky radiation (CLR) in orange.

a Pacific meridional mode characterized by SST anomalies of one sign in the northern tropical Pacific and of opposite sign over the cold tongue Chiang and Vimont (2004) is predominant at interannual time scales, whereas an ENSO-like pattern (e.g., Deser et al. 2010) is predominant at longer time scales. This hypothesis is consistent with the power spectra in Fig. 6 and with lead/lag correlations of SST in the North and South Pacific with the Niño-3 index during warm/cold events of the Niño-3 index. In fact, these composites (not shown) reveal that prior to Niño-3 warm/cold events the SST in the North and South Pacific are anticorrelated at interannual time scales, but correlated at decadal time scales. This hypothesis needs further verification with a multimodel analysis and longer simulations to rule out the possibility that this behavior is model or time dependent.

\section{c. Mechanisms of SST propagation and persistence}

Since we are examining AGCM-slab simulations, the processes that contribute to the development, propagation, and persistence of SST variability are driven solely by surface heat fluxes (i.e., shortwave, longwave, latent, and sensible). We find that the mechanisms of ENSO-like variability in our runs are consistent with previous findings (cf. Dommenget 2010; Zhang et al. 2014). Composites of ENSO-like events (not shown) reveal that an initial SST anomaly develops in the SE Pacific several months prior to the peak of the event. This anomaly propagates northward and westward via the wind-evaporation-SST feedback. The WES feedback takes place when a weakening of the climatological north-south and east-west tropical SST gradients along with a weakening of the trade winds (Fig. 4) favors a migration of SST anomaly from the SE Pacific to the eastern equatorial Pacific. Latent heat flux due to weaker northeastward trade winds initially favors the warming in the SE Pacific, but then damps SST anomalies after the event reaches its peak because of the strong dependence of latent heat release on specific humidity (Wang 2010). In contrast, the CRE contributes to the warming of SST throughout the event, reducing the damping effect of latent heat flux. In the western Pacific the CRE has opposite sign and tends to damp SST, thereby preventing the anomaly from reaching farther west.

To visualize the relative roles of the surface heat fluxes in driving ENSO-like anomalies, we composite surface heat fluxes and SST in the southeastern Pacific $\left(5^{\circ}-20^{\circ} \mathrm{S}, 70^{\circ}-100^{\circ} \mathrm{W}\right)$ prior to and after the peak of Niño-3 index warm events (Fig. 7). Figure 7 displays the processes that contribute to the growth and decay of warm SST in the SE Pacific associated with warm Niño-3 events. The Niño-3 warm events are chosen as the months at which SST is larger than one standard deviation of the Niño-3 index that are also local maxima in the time series. Figure 7a shows the composites in the control simulation, while Fig. 7b shows the composites in the SE Pacific experiment. SST (black curve) in the SE Pacific leads the peak of Niño-3 events by a few months, which is consistent with a WES feedback and northwestward propagation from the subtropical stratocumulus SE Pacific region. We note that in the SE Pacific experiment (Fig. 7b) there is a larger contribution to SST warming from the CRE, which explains 
larger-amplitude and more persistent SST anomalies than the control run (Fig. 7a). Instead, the latent heat fluxes damp SST anomalies in both simulations throughout the event. The clear-sky and sensible heat fluxes have much smaller effects. These results do not change when we apply low-pass filters to remove high-frequency variability, indicating that these mechanisms explain both interannual and low-frequency SST fluctuations in the model. The composites are not sensitive to the exact location of the box that we choose in the southeast Pacific, and compositing cold instead of warm Niño-3 events (not shown) leads to similar results.

\section{Discussion and conclusions}

In this study we examine the role of the NE and SE Pacific subtropical stratocumulus regions in driving Pacific climate variability in an AGCM (ECHAM6) coupled to a slab ocean. We enhance the strength of positive low-cloud feedback over the NE and SE Pacific by increasing the radiative effect of cloud liquid water in response to SST anomalies. We find that lowcloud feedbacks over the subtropical stratocumulus regions increase the variance and persistence of SST in the eastern Pacific Ocean, and enhance the variability of the two dominant modes of Pacific climate variability. The two dominant modes of variability correspond to a mode resembling the Pacific decadal oscillation (PDO) in the North Pacific, and a mode resembling El NiñoSouthern Oscillation (ENSO) in the equatorial eastern Pacific. We name these modes the North Pacific and South Pacific mode, respectively.

We perform two additional experiments in which we increase the strength of positive low-cloud feedback only in one of the two subtropical stratocumulus regions at the time. We find that the NE Pacific enhances the North Pacific mode but has little influence at the equator. In contrast, the SE Pacific enhances the South Pacific mode, increasing the variance of the Niño-3 index on both interannual (2-7yr) and decadal ( $>10 \mathrm{yr})$ time scales.

To understand the mechanisms contributing to the persistence of ENSO-like events, we composite heat fluxes in the southeastern Pacific during warm events of the Niño-3 index. We find that the CRE at the surface is largely responsible for the persistence of SST anomalies in the southeastern Pacific, contrasting the damping effect of latent heat fluxes. In addition to what is in the literature, we show a primary role for clouds in increasing the persistence of basinwide climate variability patterns, in particular at decadal and longer time scales.

We assert that the results of these model experiments are relevant to understanding observed decadal climate variability. In fact, decreases and increases in low cloud in the eastern subtropical Pacific cover have been observed over the last century in response to warm and cold phases of PDO, respectively (Deser et al. 2004; Clement et al. 2009). Changes in the amount of cloud cover have a strong impact on the radiative budget (Bellomo et al. 2014) and could influence SST on long time scales. Based on our results and the observational evidence for decadal shifts in cloud cover, we propose one mechanism for Pacific decadal climate variability that involves a positive feedback among cloud cover in the subtropical stratocumulus regions, SST, and largescale atmospheric circulation. This mechanism can briefly summarized as follows.

SST anomalies in the subtropical stratocumulus regions influence the strength of the trade wind and latent heat fluxes (namely, the WES feedback). The WES feedback favors a propagation of SST from the subtropical stratocumulus regions to the equator along the mean track of the trade winds. If cloud feedbacks are enhanced in the subtropical stratocumulus regions, then the variance of SST anomalies increases at longer than interannual time scales, especially at time scales longer than 10 years. These SST anomalies in the subtropical stratocumulus regions increase the persistence of basinwide SST anomalies via the WES feedback mechanism. Hence, decadal climate variability can be explained by thermally coupled heat fluxes at the ocean surface (Clement et al. 2011), but cloud feedbacks in the subtropical stratocumulus regions play an important role in setting the duration of these climate shifts. This mechanism does not presume a primary role for ocean dynamics.

In the present study we did not address the role of ocean dynamics, which remains an open question. Okumura (2013) examined the mechanisms of tropical Pacific decadal variability in both the fully coupled and slab-ocean version of Community Climate System Model, version 4 (CCSM4; Gent et al. 2011). They suggested that ocean dynamics increase the coherency of the North and the South Pacific modes by enhancing equatorial SST variability and associated atmospheric teleconnections. Ma et al. (1996) also looked at the role of ocean dynamics and showed that advection by ocean dynamics (Humboldt current) was important in the equatorward propagation of SST. These two studies both support the idea that ocean dynamics increase the variance of $\mathrm{Pa}$ cific climate variability, but Clement et al. (2011) examined an ensemble of CMIP3 slab-ocean models and showed that this effect is model dependent and generally small at time scales longer than interannual.

Finally, we note that the role of clouds in modulating climate variability is receiving increasing attention. 
A number of studies showed that atmospheric feedbacks including the cloud feedback over the cold tongue can drive ENSO events and modulate ENSO characteristics in coupled climate models, and also in observations if the cold tongue is sufficiently strong (Dommenget 2010; Bellenger et al. 2014; Dommenget et al. 2014). Some recent studies showed that subtropical stratocumulus clouds influence climate variability patterns in the Atlantic Ocean. Among others, Evan et al. (2013) showed that positive stratocumulus cloud feedbacks in the NE and SE Atlantic Ocean reduce the damping rate of SSTs associated with the Atlantic meridional mode, while Trzaska et al. (2007) suggested an important role for positive cloud feedbacks off the coasts of Namibia in propagating SST anomalies from the South Atlantic to the equatorial Atlantic.

Given the important role of cloud feedbacks in modulating climate variability in different ocean basins, we suggest that a better representation of cloud-environment relationships would potentially improve near-term predictions of interannual and decadal time scales of SST anomalies. Incorporating cloud radiative effects from satellite products in statistical prediction models such as the linear inverse model of Newman et al. (2003) or in GCMs could give insights into the predictive skill gained by including information of clouds and radiation fluxes in near-term forecasts.

Acknowledgments. We thankfully acknowledge Monika Esch, Felix Pithan, and the atmosphere group at the Max Planck Institute for Meteorology for assistance in running the simulations. We also would like to thank Ben Kirtman, Brian Soden, Paquita Zuidema, Joel Norris, and Pedro Di Nezio for helpful discussions. Carlos R. Mechoso and two anonymous reviewers provided insightful comments that helped improve the manuscript. This work is supported by the Office of Science, U.S. DOE (Grant DESC0004897), NSF Climate and Large-scale Dynamics Program (Grant AGS0946225), and the NOAA climate program office (Grant NA10OAR4310204), the Rosenstiel School's Alumni fellowship (2012), and by the Federal Ministry for Education and Research in Germany (BMBF) through the research program "MiKlip" (FKZ: 01 LP 1128B).

\section{REFERENCES}

Alexander, M., 2010: Extratropical air-sea interaction, sea surface temperature variability, and the Pacific decadal oscillation. Climate Dynamics: Why Does Climate Vary? Geophys. Monogr., Vol. 189, Amer. Geophys. Union, 123-148.

Barlow, M., S. Nigam, and E. H. Berbery, 2001: ENSO, Pacific decadal variability, and U.S. summertime precipitation, drought, and stream flow. J. Climate, 14, 2105-2128, doi:10.1175/ 1520-0442(2001)014<2105:EPDVAU>2.0.CO;2.
Bellenger, H., E. Guilyardi, J. Leloup, M. Lengaigne, and J. Vialard, 2014: ENSO representation in climate models: From CMIP3 to CMIP5. Climate Dyn., 42, 1999-2018, doi:10.1007/ s00382-013-1783-z.

Bellomo, K., A. C. Clement, J. R. Norris, and B. J. Soden, 2014: Observational and model estimates of cloud amount feedback over the Indian and Pacific Oceans. J. Climate, 27, 925-940, doi:10.1175/JCLI-D-13-00165.1.

Bony, S., and J.-L. Dufresne, 2005: Marine boundary layer clouds at the heart of tropical cloud feedback uncertainties in climate models. Geophys. Res. Lett., 32, L20806, doi:10.1029/ 2005 GL023851.

Chang, P., L. Zhang, R. Saravanan, D. J. Vimont, J. C. H. Chiang, L. Ji, H. Seidel, and M. K. Tippett, 2007: Pacific meridional mode and El Niño-Southern Oscillation. Geophys. Res. Lett., 34, L16608, doi:10.1029/2007GL030302.

Chen, J., A. D. Del Genio, B. E. Carlson, and M. G. Bosilovich, 2008: The spatiotemporal structure of twentieth-century climate variations in observations and reanalyses. Part II: Pacific pan-decadal variability. J. Climate, 21, 2611-2633, doi:10.1175/ 2007JCLI2012.1.

Chiang, J. C. H., and D. J. Vimont, 2004: Analogous Pacific and Atlantic meridional modes of tropical atmosphere-ocean variability. J. Climate, 17, 4143-4158, doi:10.1175/JCLI4953.1.

Clement, A. C., R. Burgman, and J. Norris, 2009: Model and observational evidence for positive low-level cloud feedback. Science, 325, 460-464, doi:10.1126/science.1171255.

, P. DiNezio, and C. Deser, 2011: Rethinking the ocean's role in the Southern Oscillation. J. Climate, 24, 4056-4072, doi:10.1175/2011JCLI3973.1.

Cronin, M. F., N. A. Bond, C. W. Fairall, and R. A. Weller, 2006: Surface cloud forcing in the east Pacific stratus deck/cold tongue/ ITCZ complex. J. Climate, 19, 392-409, doi:10.1175/JCLI3620.1.

Deser, C., A. Phillips, and J. Hurrell, 2004: Pacific interdecadal climate variability: Linkages between the tropics and North Pacific during boreal winter since 1900. J. Climate, 17, 31093124, doi:10.1175/1520-0442(2004)017<3109:PICVLB >2.0.CO;2. , M. A. Alexander, S.-P. Xie, and A. S. Phillips, 2010: Sea surface temperature variability: Patterns and mechanisms. Annu. Rev. Mar. Sci., 2,115-143, doi:10.1146/annurev-marine-120408-151453. de Szoeke, S., S. Yuter, D. Mechem, C. W. Fairall, C. D. Burleyson, and P. Zuidema, 2012: Observations of stratocumulus clouds and their effect on the eastern Pacific surface heat budget along $20^{\circ}$ S. J. Climate, 25, 8542-8567, doi:10.1175/JCLI-D-11-00618.1.

Di Lorenzo, E., and Coauthors, 2008: North Pacific Gyre Oscillation links ocean climate and ecosystem change. Geophys. Res. Lett., 35, L08607, doi:10.1029/2007GL032838.

Dommenget, D., 2010: The slab ocean El Niño. Geophys. Res. Lett., 37, L20701, doi:10.1029/2010GL044888. , and M. Latif, 2008: Generation of hyper climate modes. Geophys. Res. Lett., 35, L02706, doi:10.1029/2007GL031087.

— - S. Haase, T. Bayr, and C. Frauen, 2014: Analysis of the slab ocean El Niño atmospheric feedbacks in observed and simulated ENSO dynamics. Climate Dyn., doi:10.1007/ s00382-014-2057-0, in press.

Evan, A. T., R. J. Allen, D. J. Vimont, and R. Bennartz, 2013: The modification of sea surface temperature anomaly linear damping time scales by stratocumulus clouds. J. Climate, 26, 36193630, doi:10.1175/JCLI-D-12-00370.1.

Frankignoul, C., and K. Hasselmann, 1977: Stochastic climate models, Part II. Application to sea-surface temperature variability and thermocline variability. Tellus, 29, 289-305, doi:10.1111/ j.2153-3490.1977.tb00740.x. 
Gent, P. R., and Coauthors, 2011: The Community Climate System Model version 4. J. Climate, 24, 4973-4991, doi:10.1175/ 2011JCLI4083.1.

Gu, D., and S. G. H. Philander, 1997: Internal climate fluctuations that depend on exchanges between the tropics and extratropics. Science, 275, 805-807, doi:10.1126/science.275.5301.805.

Hare, S. R., and N. J. Mantua, 2000: Empirical evidence for North Pacific regime shifts in 1977 and 1989. Prog. Oceanogr., 47, 103-145, doi:10.1016/S0079-6611(00)00033-1.

Hoerling, M. P., J. W. Hurrell, and T. Y. Xu, 2001: Tropical origins for recent North Atlantic climate change. Science, 292, 90-92, doi:10.1126/science.1058582.

Karspeck, A. R., R. Seager, and M. A. Cane, 2004: Predictability of tropical Pacific decadal variability in an intermediate model. J. Climate, 17, 2842-2850, doi:10.1175/1520-0442(2004)017<2842: POTPDV $>2.0 . \mathrm{CO} ; 2$.

Kim, H.-M., P. J. Webster, and J. A. Curry, 2012: Evaluation of short-term climate change prediction in multi-model CMIP5 decadal hindcasts. Geophys. Res. Lett., 39, L10701, doi:10.1029/ 2012GL051644.

Klein, S. A., and D. L. Hartmann, 1993: The seasonal cycle of low stratiform clouds. J. Climate, 6, 1587-1606, doi:10.1175/ 1520-0442(1993)006<1587:TSCOLS > 2.0.CO;2.

Kwon, Y.-O., and C. Deser, 2007: North Pacific decadal variability in the Community Climate System Model version 2. J. Climate, 20, 2416-2433, doi:10.1175/JCLI4103.1.

Latif, M., and T. P. Barnett, 1994: Causes of decadal climate variability over the North Pacific and North America. Science, 266, 634-637, doi:10.1126/science.266.5185.634.

Lauer, A., K. Hamilton, Y. Wang, V. T. J. Phillips, and R. Bennartz, 2010: The impact of global warming on marine boundary layer clouds over the eastern Pacific-A regional model study. $J$. Climate, 23, 5844-5863, doi:10.1175/2010JCLI3666.1.

Loeb, N. G., B. A. Wielicki, D. R. Doelling, G. L. Smith, D. F. Keyes, S. Kato, N. Manalo-Smith, and T. Wong, 2009: Toward optimal closure of the Earth's top-of-atmosphere radiation budget. J. Climate, 22, 748-766, doi:10.1175/2008JCLI2637.1.

Ma, C. C., C. R. Mechoso, A. W. Robertson, and A. Arakawa, 1996: Peruvian stratus clouds and the tropical Pacific circulation: A coupled ocean-atmosphere GCM study. J. Climate, 9, 16351645, doi:10.1175/1520-0442(1996)009<1635:PSCATT >2.0.CO;2.

Mantua, N. J., and S. R. Hare, 2002: The Pacific decadal oscillation. J. Oceanogr., 58, 35-44, doi:10.1023/A:1015820616384.

, _ Y. Zhang, J. M. Wallace, and R. C. Francis, 1997: A Pacific interdecadal climate oscillation with impacts on salmon production. Bull. Amer. Meteor. Soc., 78, 1069-1079, doi:10.1175/1520-0477(1997)078<1069:APICOW>2.0.CO;2.

Matei, D., N. Keenlyside, M. Latif, and J. Jungclaus, 2008: Subtropical forcing of tropical Pacific climate and decadal ENSO modulation. J. Climate, 21, 4691-4709, doi:10.1175/ 2008JCLI2075.1.

McCabe, G. J., M. A. Palecki, and J. L. Betancourt, 2004: Pacific and Atlantic Ocean influences on multidecadal drought frequency in the United States. Proc. Natl. Acad. Sci. USA, 101, 4136-4141, doi:10.1073/pnas.0306738101.

Medeiros, B., and B. Stevens, 2011: Revealing differences in GCM representations of low clouds. Climate Dyn., 36, 385-399, doi:10.1007/s00382-009-0694-5.

Minobe, S., 1997: A 50-70 year climatic oscillation over the North Pacific and North America. Geophys. Res. Lett., 24, 683-686, doi:10.1029/97GL00504.

Newman, M., G. P. Compo, and M. A. Alexander, 2003: ENSO-forced variability of the Pacific decadal oscillation.
J. Climate, 16, 3853-3857, doi:10.1175/1520-0442(2003)016<3853: EVOTPD $>2.0 . \mathrm{CO} ; 2$.

Nigam, S., 1997: The annual warm to cold phase transition in the eastern equatorial Pacific: Diagnosis of the role of stratus cloud-top cooling. J. Climate, 10, 2447-2467, doi:10.1175/ 1520-0442(1997)010<2447:TAWTCP > 2.0.CO;2.

Nitta, T., and S. Yamada, 1989: Recent warming of tropical sea surface temperature and its relationship to the Northern Hemisphere circulation. J. Meteor. Soc. Japan, 67, 375-382.

Norris, J. R., 2005: Trends in upper-level cloud cover and surface divergence over the tropical Indo-Pacific Ocean between 1952 and 1997. J. Geophys. Res., 110, D21110, doi:10.1029/ 2005JD006183.

Okumura, Y. M., 2013: Origins of tropical Pacific decadal variability: Role of stochastic atmospheric forcing from the South Pacific. J. Climate, 26, 9791-9796, doi:10.1175/ JCLI-D-13-00448.1.

Park, S., C. Deser, and M. A. Alexander, 2005: Estimation of the surface heat flux response to sea surface temperature anomalies over the global oceans. J. Climate, 18, 4582-4599, doi:10.1175/JCLI3521.1.

Peterson, W. T., and F. B. Schwing, 2003: A new climate regime in northeast Pacific ecosystems. Geophys. Res. Lett., 30, 1896, doi:10.1029/2003GL017528.

Philander, S. G. H., D. Gu, D. Halpern, G. Lambert, N.-C. Lau, T. Li, and R. C. Pacanowski, 1996: Why the ITCZ is mostly north of the equator. J. Climate, 9, 2958-2972, doi:10.1175/ 1520-0442(1996)009<2958:WTIIMN>2.0.CO;2.

Schubert, S. D., M. J. Suarez, P. J. Pegion, R. D. Koster, and J. T. Bacmeister, 2004a: On the cause of the 1930s Dust Bowl. Science, 303, 1855-1859, doi:10.1126/science.1095048.

,,,$--- \ldots$, and,$- 2004 \mathrm{~b}$ : Causes of long-term drought in the U.S. Great Plains. J. Climate, 17, 485-503, doi:10.1175/1520-0442(2004)017<0485:COLDIT > 2.0.CO;2.

Seager, R., Y. Kushnir, C. Herweijer, N. Naik, and J. Velez, 2005: Modeling of tropical forcing of persistent droughts and pluvials over western North America: 1856-2000. J. Climate, 18, 4065-4088, doi:10.1175/JCLI3522.1.

Smith, D. M., A. A. Scaife, and B. P. Kirtman, 2012: What is the current state of scientific knowledge with regard to seasonal and decadal forecasting? Environ. Res. Lett., 7, 015602, doi:10.1088/1748-9326/7/1/015602.

Smith, T. M., R. W. Reynolds, T. C. Peterson, and J. Lawrimore, 2008: Improvements to NOAA's historical merged landocean surface temperature analysis (1880-2006). J. Climate, 21, 2283-2296, doi:10.1175/2007JCLI2100.1.

Stevens, B., and Coauthors, 2013: The atmospheric component of the MPI-M Earth System Model: ECHAM6. J. Adv. Model Earth Syst., 5, 146-172, doi:10.1002/jame.20015.

Timmermann, A., and F. Jin, 2002: A nonlinear mechanism for decadal El Niño amplitude changes. Geophys. Res. Lett., 29, 1003, doi:10.1029/2001GL013369.

Trenberth, K. E., and J. W. Hurrell, 1994: Decadal atmosphericocean variations in the Pacific. Climate Dyn., 9, 303-319, doi:10.1007/BF00204745.

Trzaska, S., A. W. Robertson, J. D. Farrara, and C. R. Mechoso, 2007: South Atlantic variability arising from air-sea coupling: Local mechanisms and tropical-subtropical interactions. J. Climate, 20, 3345-3365, doi:10.1175/JCLI4114.1.

Wang, C., C. Deser, J.-Y. Yu, P. DiNezio, and A. Clement, 2014: El Niño and Southern Oscillation (ENSO): A review. Coral Reefs of the Eastern Pacific, P. Glynn, D. Manzello and I. Enochs, Eds., Springer-Verlag, in press. 
Wang, F., 2010: Thermodynamical coupled modes in the tropical atmosphere-ocean: An analytical solution. J. Atmos. Sci., 67, 1667-1677, doi:10.1175/2009JAS3262.1.

Wang, X. L., and C. F. Ropelewski, 1995: An assessment of ENSOscale secular variability. J. Climate, 8, 1584-1599, doi:10.1175 1520-0442(1995)008<1584:AAOESS > 2.0.CO;2.

Yeh, S.-W., and B. P. Kirtman, 2006: Origin of decadal El NiñoSouthern Oscillation-like variability in a coupled general circulation model. J. Geophys. Res., 111, C01009, doi:10.1029/ 2005JC002985.
Zhang, H., A. Clement, and P. Di Nezio, 2014: The South Pacific meridional mode: A mechanism for ENSO-like variability. J. Climate, 27, 769-783, doi:10.1175/JCLI-D-13-00082.1.

Zhang, Y., J. M. Wallace, and D. S. Battisti, 1997: ENSO-like interdecadal variability: 1900-93. J. Climate, 10, 1004-1020, doi:10.1175/1520-0442(1997)010<1004:ELIV>2.0.CO;2.

Zhou, Z., and J. A. Carton, 1998: Latent heat flux and interannual variability of the coupled atmosphere-ocean system. J. Atmos. Sci., 55, 494-501, doi:10.1175/1520-0469(1998)055<0494: LHFAIV $>2.0 . \mathrm{CO} ; 2$. 